\section{The thyroid hormone receptor $\beta$-selective agonist GC-1 does not affect tolerance to exercise in hypothyroid rats}

Alexandre Gonçalves', Chineyder Corrêa Tolentino², Fernanda Rodrigues de Souza ${ }^{3}$, Juliana Carla da Costa Huss, Karolinne de Lourdes Zinato ${ }^{5}$, Leandro Teixeira Paranhos Lopes ${ }^{3}$, Roberto Furlanetto Júnior ${ }^{6}$, Francisco de Assis Rocha Neves ${ }^{7}$

\begin{abstract}
Objective: Investigate the effect of GC-1 on tolerance to exercise in rats with experimental hypothyroidism. Materials and methods: Hypothyroidism was induced with methimazole sodium and perchlorate treatment. Six groups with eight animals were studied: control group (C), hypothyroid group without treatment (HYPO); hypothyroidism treated with physiological doses of tetraiodothyronine $\left(T_{4}\right)$ or 10 times higher $\left(10 \times T_{4}\right)$; hypothyroidism treated with equal molar doses of GC-1 (GC-1) or 10 times higher (10xGC-1). After eight weeks, each animal underwent an exercise tolerance test by measuring the time (seconds), in which the rats were swimming with a load attached to their tails without being submerging for more than $10 \mathrm{sec}$. After the test, the animals were killed, and blood samples were collected for biochemical analysis, and the heart and soleus muscle were removed for weighing and morphometric analysis of the cardiomyocyte. Results: Hypothyroidism significantly reduced tolerance to exercise and, treatment with GC-1 $1 \times$ or $\mathrm{T}_{4}$ in physiological doses recover tolerance test to normal parameters. However, high doses of $\mathrm{T}_{4}$ also decreased tolerance to physical exercise. Conversely, ten times higher doses of GC-1 did not impair tolerance to exercise. Interestingly, hypothyroidism, treated or not with T4 in a physiological range, GC-1 or even high doses of GC-1 (10X) did not change cardiomyocyte diameters and relative weight of the soleus muscle. In contrast, higher doses of $\mathrm{T}_{4}$ significantly increased cardiomyocyte diameter and induced atrophy of the soleus muscle. Conclusion: Unlike $\mathrm{T}_{4^{\prime}}, \mathrm{GC}-1$ in high doses did not modify tolerance to physical exercise in the rats with hypothyroidism. Arch Endocrinol Metab. 2015;59(2):141-7
\end{abstract}

Keywords

GC-1; exercise; thyroid; hypothyroidism
1 Post Graduation in Health Sciences, Faculty of Health Sciences, University of Brasilia (UnB), Brasilia, DF, Brazil ${ }^{2}$ Institute of Health Sciences, University Centre of Planalto de Araxa, Araxa, MG, Brazil ${ }^{3}$ Post-Graduate in Health Sciences, Faculty of Medicine, Federal University of Uberlandia (UFU), Uberlandia, MG, Brazil ${ }^{4}$ Post-Graduate in Genetics and Biochemistry, Institute of Genetics and Biochemistry, UFU, Uberlandia, MG, Brazil ${ }^{5}$ Institute of Health Sciences, Central University of Planalto de Araxa, Araxa, MG, Brazil ${ }^{6}$ Post-Graduate in Physical Education, Faculty of Physical Education, Federal University of Triangulo Mineiro, Uberaba, MG, Brazil

${ }^{7}$ Molecular Pharmacology Laboratory, Faculty of Health Sciences, UnB, Brasilia, DF, Brazil

Correspondence to: Alexandre Gonçalves QE 24, cj. G, casa 18, Guará II 71070-060 - Brasília, DF, Brazil alexandreunb@yahoo.com.br

Received on Aug/29/2014 Accepted on Oct/20/2014 DOI: $10.1590 / 2359-3997000000027$

\section{INTRODUCTION}

$\mathrm{T}$ hyroid hormones (THs) act on practically all human organ systems, playing an important role in growth and development, and regulation of diverse homeostatic functions, including production of heat and energy. THs modulate myocardial function, metabolic rate, mineral bone density, lipid regulation, and cholesterol and lipoprotein metabolism (1-4). To initiate these effects, $\mathrm{TH}$ enter the target cell through a system mediated by transporters to bind to $\mathrm{TH}$ receptor [TR] located in the nucleus. These receptors are distributed in various tissues, and the affinity to TR is ten times greater for 3,5,3'-triiodothyronine $\left(\mathrm{T}_{3}\right)$ than for $3,5,3^{\prime}, 5^{\prime}$-tetraiodothyronine $\left(\mathrm{T}_{4}\right)$. The actions of THs are mediated by two different recep- tors, namely receptor $\alpha(\operatorname{TR} \alpha)$ and receptor $\beta(\operatorname{TR} \beta)$ (5). TR $\alpha$ and $\beta$ are coded by two different genes located on chromosomes 17 and 3 , respectively. The isoforms $\alpha 1, \beta 1, \beta 2$, and $\beta 3$, which result from the alternative splicing of messenger RNA or use of alternative promoters, are capable of binding to $\mathrm{THs}$ and are heterogeneously distributed in diverse tissues (6). TR $\beta 1$ is predominant in the kidney, brain, and liver, where it plays a role in the metabolism of blood cholesterol and energy expenditure. TR $\beta 2$ is expressed only in the brain and anterior pituitary, where it regulates the negative feedback mechanism of the TH in the hypothalamic-pituitary-thyroid axis. TR $\alpha \mathrm{l}$ is predominately expressed in the central nervous system, myocardium, gastrointestinal tract, skeletal muscle, 
cartilage, and bone (3-8). Given that $\mathrm{T}_{3}$ has a similar affinity to $\operatorname{TR} \beta$ and $\operatorname{TR} \alpha$, even though the distributions of TRs differ, the administration of THs is restricted for the treatment of hypothyroidism, as it can cause serious adverse effects such as tachycardia and cardiac arrhythmias, which are associated with TR $\alpha$ stimulation in the heart (6-9).

However, as the $\mathrm{TH}$ increases energy expenditure and significantly decreases the levels of cholesterol and lipoproteins, several groups have tried to develop selective agonists of the $\beta$ thyroid receptor, given that these ligands may help treat diseases such as obesity and dyslipidemia $(10,11)$. Owing to their lower affinity to TR $\alpha$ l, selective agonists for $T R \beta$ do not cause, for example, tachycardia. Thus, various compounds with selective action for $\operatorname{TR} \beta$ were synthesized, including [3,5-dimethyl-4-(4'-hydroxy$3^{\prime}$-isopropylbenzyl)]-phenoxyacetic acid, known as GC-1 (12).

Studies have already shown that GC-1 effectively decreases obesity, increases metabolic rate and lipolysis, and decreases plasma levels of cholesterol, lipoproteins, and triglycerides without increasing cardiac frequency $(13,14)$. In addition, unlike THs, the use of GC-1 does not induce osteoporosis or damage the skeletal tissue of rodents $(15,16)$. Administrating GC-1 or GC-24, another TR $\beta$-selective compound, to rats with hypothyroidism did not affect muscle mass (16), genetic expression, or composition of muscle fibers (17).

Despite the positive effects of selective TR $\beta$ agonists on metabolic rate and lipid profile already being well demonstrated in the literature, studies on cardiac side effects are more restricted to assessing the increase in cardiac frequency and/or presence of arrhythmias $(13,14,18)$.

To date, no study has investigated the influence of selective TR $\beta 1$ agonists on tolerance to physical exercise, despite that both hypothyroidism and hyperthyroidism are known to affect their role during exercise $(19,20)$.

The aim of this study was to analyze the effect of GC-1 on tolerance to exercise in rats with experimental hypothyroidism that were submitted to swimming sessions. We assessed the tolerance to exercise in swimming sessions in hypothyroid rats treated with $\mathrm{T}_{4}$ and GC-1 in physiological and supraphysiological doses. Our results revealed that GC-1, unlike $\mathrm{T}_{4}$, even in high doses, did not affect tolerance to physical exercise.

\section{MATERIALS AND METHODS}

\section{Animals and drugs}

This study was approved by the Animal Ethics Committee (CEUA) at the Institute of Biological Sciences at the University of Brasilia, Brasilia, Brazil (approval No. 119158/2010). To implement the experimental protocol, adult Wistar rats from the bioterium of the Federal University of Uberlandia, Uberlandia, MG, Brazil weighing between 200 to $250 \mathrm{~g}$ were used. We selected 48 animals, which were divided into six groups of eight animals as it follows: the euthyroid control group (C), hypothyroid group (HYPO), hypothyroid group treated with $\mathrm{T}_{4}$ (Sigma, Brazil) (T4) at a dose of $0.3 \mu \mathrm{g} / \mathrm{l} 00 \mathrm{~g}$ of body weight $(\mathrm{BW})$ per day, treated with $10 \times \mathrm{T}_{4}$ at a dose of $3 \mu \mathrm{g} / 100 \mathrm{~g}$ of BW per day (group 10×T4), treated with GC-1 at a dose of $0.15 \mu \mathrm{g} / 100 \mathrm{~g}$ of BW per day (group GC-1), and treated with $10 \times \mathrm{GC}-1$ at a dose of $1.5 \mu \mathrm{g} / 100 \mathrm{~g}$ of BW per day (group $10 \times \mathrm{GC}-1$ ). The GC-1 and $10 \times \mathrm{GC}-1$ groups were treated with equimolar doses of groups $\mathrm{T} 4$ and $10 \times \mathrm{T} 4 . \mathrm{T}_{4}$ was dissolved in 40 $\mathrm{mol} / \mathrm{L} \mathrm{NaOH}$, and GC-1 was dissolved in dimethyl sulfoxide at a concentration of $1 \mathrm{mg} / \mathrm{mL}$. Then, both $\mathrm{T}_{4}$ and GC-1 were diluted in a saline solution. All the treatments were administered via daily intraperitoneal injections for a period of eight weeks. All the animals were weighed every three days to adjust the doses of the drugs when required.

\section{Storing the animals}

The animals were kept in cages in the bioterium at the Central University of Planalto de Araxa, MG, Brazil. The temperature, relative air humidity, and level of noise were kept constant throughout the experiment, with the light-dark cycle every 12 hours. All the animals received food and water ad libitum.

\section{Induction of hypothyroidism}

Hypothyroidism was induced by administering $0.1 \%$ methimazole plus $1 \%$ sodium perchlorate (MM 0.1\% $+\mathrm{P} 1 \%)$ in the drinking water of the rats during the experiment $(21)$.

\section{Effort test}

Before the effort test was applied, the animals spent five days adapting to the aquatic environment. The swimming apparatus for the effort test was a $20 \times 50 \mathrm{~cm}$ tank, filled with water between $30^{\circ} \mathrm{C}$ and $32^{\circ} \mathrm{C}$ up to $40 \mathrm{~cm}$, thereby preventing the rats from floating during the test. 
To verify the exercise tolerance, the following protocol was used as follows: each animal underwent a swimming session, with a load representing $5 \%$ of its BW attached to its tail, for as long as possible. This procedure guarantees an intensity of effort corresponding to the maximum stable phase of lactate. The test was validated when the rats were submerged for more than $10 \mathrm{sec}$. Tolerance to effort was defined as the time that the animals spent swimming without being submerged for more than $10 \mathrm{sec}(22)$.

\section{Blood collection and analysis of hormone levels}

After performed the effort tolerance test, the animals were euthanized by decapitation using a guillotine and blood samples were collected from the trunk. Each blood sample was centrifuged and immediately frozen. Subsequently, the total serum levels of $\mathrm{T}_{3}, \mathrm{~T}_{4}$, and TSH were analyzed in the Clinical Analysis Laboratory of the Veterinary Hospital at the Federal University of Uberlandia, using enzyme-linked immunosorbent assay. Intra and inter-assay coefficients of variation were respectively: $\mathrm{T}_{3}=9,6-10,3 \%, \mathrm{~T}_{4}=4,3-4,5 \%, \mathrm{TSH}=4,6-7,6 \%$.

\section{Removal and weighing of the heart and soleus muscle}

After being euthanized by decapitation, the thorax was opened, and the left posterior limb was dismembered to remove the heart and soleus muscle, respectively, which were then fixed in 10\% formalin. After 24 hours, both the heart and soleus muscle were weighed using a Filizolla precision balance $(0.001 \mathrm{~g}$-Gehaka Ltda. Sao Paulo-Brazil). The relative weights of the cardiac and soleus muscles were determined by dividing the respective values obtained from the total weight of the animal on the day of euthanasia.

Afterward, the left ventricle was removed together with the interventricular septum to perform the histological sections. This procedure aims to verify possible hypertrophy or tissue degradation.

\section{Histomorphometric analysis of the heart}

The histological samples were prepared by immersing the material in paraffin, followed by hydration (deparaffinization) and finally dehydration of the material (diaphanization).

Next, two sections of the right ventricle were formed, and the smallest diameters of seven perpendicularly cut cells were measured and identified in five different microscopic fields. The cell diameter was measured using scanned images taken using a binocular Olympus BX40 microscope at 40× resolution, coupled to an Olympus OLY-200 camera attached to a computer via a Data Translation 3153 digital board. The measurements were performed using the software HL Image (Western Vision). The whole analysis was performed using the double-blind technique. All the procedures to prepare the slides and equipment to analyze the material belonged to the Laboratory of Histology and Molecular Biology of the Institute of Biomedical Sciences at the Federal University of Uberlandia.

\section{Statistical analysis}

The data were statistically analyzed using the software Prism 4.0. One-way analysis of variance was used to verify any significant difference between the groups, followed by the Newman-Keuls test, with a significance level of 0.05 .

\section{RESULTS}

\section{Serum levels of $\mathrm{T}_{3}, \mathrm{~T}_{4}$, and TSH}

As shown in table 1 , the serum levels of $\mathrm{T}_{3}$ and $\mathrm{T}_{4}$ were significantly lower, and that of TSH was significantly higher in the hypothyroid group than in the control group. Treatment with $\mathrm{T}_{4}$ in physiological doses normalized the $\mathrm{T}_{3}, \mathrm{~T}_{4}$, and TSH levels. Meanwhile, treatment with high doses of $\mathrm{T}_{4}(10 \times \mathrm{T} 4)$ significantly increased the serum $\mathrm{T}_{3}$ and $\mathrm{T}_{4}$ levels and decreased the TSH levels. The animals treated with GC-1 (GC-1 and $10 \times \mathrm{GC}-1)$ had lower serum $\mathrm{T}_{3}$ and $\mathrm{T}_{4}$ levels than the control group. The serum TSH level was lower only for $10 \times \mathrm{GC}-1$.

Table 1. Serum levels of thyroid hormones in the different groups

\begin{tabular}{lccc}
\hline $\begin{array}{l}\text { Groups/ } \\
\text { Parameters }\end{array}$ & $\mathbf{T}_{\mathbf{3}}$ (ng/dL) & $\mathbf{T}_{\mathbf{4}}(\mathbf{n g} / \mathbf{m L})$ & TSH $(\boldsymbol{\mu U} / \mathbf{d L})$ \\
\hline C & $1.68 \pm 0.25$ & $46,58 \pm 2.40$ & $0.22 \pm 0.01$ \\
HYPO & $0.18 \pm 0.07^{\mathrm{a}}$ & $5.60 \pm 0.50^{\mathrm{a}}$ & $0.80 \pm 0.03^{\mathrm{a}}$ \\
T4 & $1.30 \pm 0.18^{\mathrm{b}}$ & $49.65 \pm 3.26^{\mathrm{b}}$ & $0.18 \pm 0.02^{\mathrm{b}}$ \\
10xT4 & $2.10 \pm 0.07^{\mathrm{a}, \mathrm{b}, \mathrm{c}}$ & $155.56 \pm 5.78^{\mathrm{a}, \mathrm{b}, \mathrm{c}}$ & $0.02 \pm 0.0^{\mathrm{a}, \mathrm{b}, \mathrm{c}}$ \\
GC-1 & $0.3 \pm 0.10^{\mathrm{a}, \mathrm{c}, \mathrm{d}}$ & $4.29 \pm 1.08^{\mathrm{a}, \mathrm{c}, \mathrm{d}}$ & $0.16 \pm 0.02^{\mathrm{b}, \mathrm{d}}$ \\
10'GC-1 & $0.62 \pm 0.16^{\mathrm{a}, \mathrm{c}, \mathrm{d}}$ & $10.13 \pm 1.06^{\mathrm{a}, \mathrm{c}, \mathrm{d}}$ & $0.06 \pm 0.02^{\mathrm{a}, \mathrm{b}, \mathrm{c}, \mathrm{e}, \mathrm{e}}$ \\
\hline
\end{tabular}

The values correspond to mean \pm standard error. For each value, eight rats were used. $T_{3}=$ Serum levels of $\mathrm{T}_{3} ; \mathrm{T}_{4}=$ Serum levels of $\mathrm{T}_{4} ; \mathrm{TSH}=$ Serum levels of $\mathrm{TSH} ; \mathrm{C}=$ control group; HYPO = hypothyroid rats; $\mathrm{T}_{4}=$ hypothyroid rats treated with $\mathrm{T}_{4} ; 10 \times \mathrm{T}_{4}=$ hypothyroid rats treated with $10 \times \mathrm{T}_{4} ; \mathrm{GC}-1$ = hypothyroid rats treated with $\mathrm{GC}-1 ; 10 \times \mathrm{GC}-1=$ hypothyroid rats treated with $10 \times G C-1 . \mathbf{a}=$ significant difference when compared to group $\mathrm{C} ; \mathbf{b}=$ significant difference when compared to group HYPO; $\mathbf{c}=$ significant difference when compared to group $\mathrm{T} 4 ; \mathbf{d}=$ significant difference when compared to group $10 \times \mathrm{T} 4$; and $\mathbf{e}=$ significant difference when compared to group GC-1. $p \leq 0.05$ in the Newman-Keuls test. 


\section{Tolerance to the effort test}

To address the response of each group to physical effort, the animals performed exercise in the form of swimming, with a load equivalent to $5 \%$ of their BW. As can be seen in figure 1 , hypothyroidism decreased tolerance to physical exercise rather significantly. The control animals managed to swim for $426.75 \pm 42.72$ $\mathrm{sec}$, whereas the group with hypothyroidism tolerated only $110.13 \pm 5.78 \mathrm{sec}(\mathrm{p}<0.001)$. Treating the animals with $\mathrm{T}_{4}$ or GC-1 normalized tolerance to exercise $(\mathrm{T} 4=414.63 \pm 36.40 \mathrm{sec} ; \mathrm{GC}-1=398.13 \pm 21.71$ sec). However, when the animals were treated with higher doses of $\mathrm{T}_{4}(10 \times \mathrm{T} 4)$, tolerance to exercise also decreased quite significantly, reaching values similar to those in hypothyroidism $(212 \pm 22.57 \mathrm{sec} ; \mathrm{p}<0.001)$. Unlike $\mathrm{T}_{4}$, GC-1 at higher doses did not alter the tolerance of the animals to swimming $(455.75 \pm 25.58 \mathrm{sec})$.

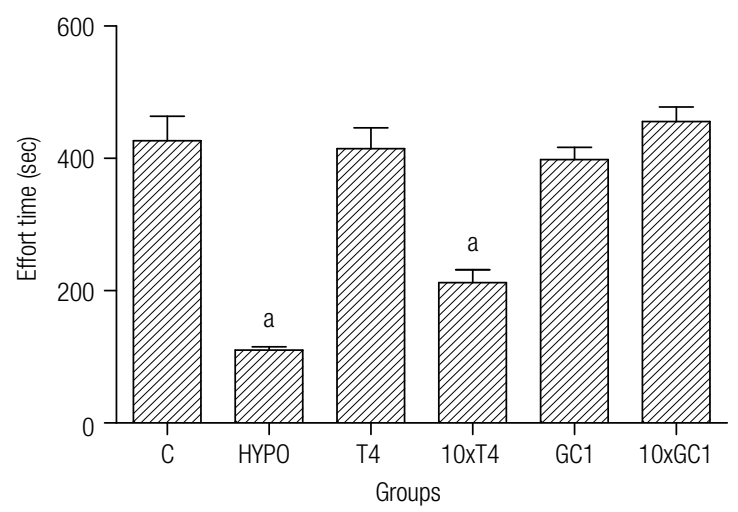

Figure 1. GC-1 did not alter tolerance to physical effort in the hypothyroid Wistar rats subjected to the swimming protocol, with a load equivalent to $5 \%$ of body weight ( $n=8$ rats per group). Control $(C)$; with untreated hypothyroidism (HYPO); with hypothyroidism treated with T4 in physiological doses (T4); high doses (10×T4); and with equimolar doses of GC-1 (GC-1 and $10 \times G C-1)$. The effort time was when the animals managed to swim without being submerged for more than $10 \mathrm{sec}$. $\mathbf{a}=$ significant difference when compared to the control group. $p \leq 0.05$ in the Newman-Keuls test.

\section{Body parameters of the rats with experimentally induced hypothyroidism}

Hypothyroidism caused a significant increase in BW and treatment with $\mathrm{T}_{4}$, GC- 1 and $10 \times$ GC- 1 normalized these values (Table 2). However, using $\mathrm{T}_{4}$ at high doses $(10 \times \mathrm{T} 4)$ caused a significant decrease in $\mathrm{BW}$.

Hypothyroidism induced a significant increase in the weight of the heart when compared with the rest of the animals, whereas groups $\mathrm{T} 4,10 \times \mathrm{T} 4$, and $10 \times \mathrm{GC}-1$ did not show different values to the control group. When analyzing the heart weight corrected by BW, a significant increase was observed only for group $10 \times \mathrm{T} 4$.
Table 2. Effect of treatment with $\mathrm{T}_{4}$ and $\mathrm{GC}-1$ on the body parameters of the rats with experimentally induced hypothyroidism

\begin{tabular}{lccc}
\hline $\begin{array}{l}\text { Groups/ } \\
\text { Parameters }\end{array}$ & BW (g) & HW $(\mathbf{m g})$ & $\begin{array}{c}\text { HW/BW } \\
\mathbf{( m g / g )}\end{array}$ \\
\hline C & $310.38 \pm 10.67$ & $970 \pm 26.64$ & $3.13 \pm 0.09$ \\
HYPO & $451.75 \pm 15.17^{\mathrm{a}}$ & $1572.5 \pm 80.84^{\mathrm{a}}$ & $3.48 \pm 0.14$ \\
T4 & $337.50 \pm 8.9^{\mathrm{b}}$ & $1052.50 \pm 30.62^{\mathrm{b}}$ & $3.13 \pm 0.11$ \\
10xT4 & $233.38 \pm 15.22^{\mathrm{a}, \mathrm{b}, \mathrm{c}}$ & $886.25 \pm 34.57^{\mathrm{b}, \mathrm{c}}$ & $3.85 \pm 0.2^{\star}$ \\
GC-1 & $341.38 \pm 11.17^{\mathrm{b}, \mathrm{d}}$ & $1142.5 \pm 26.98^{\mathrm{a}, \mathrm{b}, \mathrm{d}}$ & $3.36 \pm 0.09$ \\
10'GC-1 & $312.63 \pm 18.07^{\mathrm{b}, \mathrm{d}}$ & $1020 \pm 29.28^{\mathrm{b}, \mathrm{d}}$ & $3.32 \pm 0.21$ \\
\hline
\end{tabular}

The values correspond to mean \pm standard error. For each value, 8 rats were used. $\mathrm{BW}=$ body weight of the rats; $\mathrm{HW}=$ rat heart weight; $\mathrm{HW} / \mathrm{BW}=$ relative weight of the rat heart. $\mathrm{C}=$ control group; $\mathrm{HYPO}=$ hypothyroid rats; $\mathrm{T} 4=$ hypothyroid rats treated with $\mathrm{T} 4 ; 10 \times \mathrm{T} 4=$ hypothyroid rats treated with $10 \times \mathrm{T} 4 ; \mathrm{GC}-1=$ hypothyroid

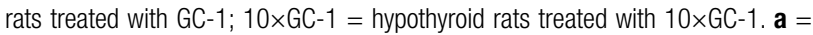
significant difference when compared to $\mathbf{C}$. $\mathbf{b}=$ significant difference when compared to HYPO. $\mathbf{c}=$ Significant difference when compared to T4. $\mathbf{d}=$ Significant difference when compared to $10 \times \mathrm{T} 4$. ${ }^{*}$ Significant difference when compared to the other groups.

\section{Diameter of cardiomyocytes}

Given that BW varies significantly when hypothyroidism or hyperthyroidism is present and that heart weight corrected by BW may vary according to BW changes, we decided to analyze cardiomyocyte diameter in the different groups. As observed in figure 2, compared with the controls, the rats with hypothyroidism did not have altered cardiomyocyte diameters. Similarly, treatment with $\mathrm{T}_{4}$ and GC-1 in normal doses also did not cause such alteration. However, administering $\mathrm{T}_{4}$ in high doses (group 10×T4) significantly increased cardiomyocyte diameter. On the other hand, high doses of GC-1 did not modify cardiomyocyte diameters (10×GC-1).

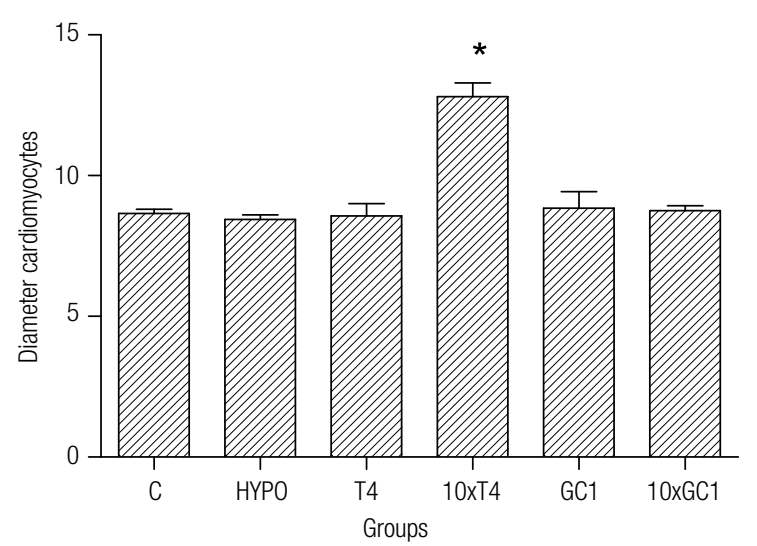

Figure 2. GC-1 did not alter cardiomyocyte diameter in the rats treated with physiological (GC-1) and high doses (10×GC-1; $n=8$ rats per group). The diameter of the cardiomyocytes of the left ventricle was measured in the animals in the different groups. ${ }^{*}$ Significant difference in group $10 \times T 4$ when compared to the rest. $p<0.05$ in the Newman-Keuls test. 


\section{Relative weight of the soleus muscle}

Next, to analyze the influence of the different treatments on skeletal musculature, the relative weight of the soleus muscle was analyzed for each animal. As shown in figure 3, hypothyroidism did not alter the relative weight of the soleus muscle, nor did treatment with $\mathrm{T}_{4}$ and GC-1 in physiological doses. Meanwhile, administering $\mathrm{T}_{4}$ in high doses caused atrophy of the soleus muscle. Conversely, the administration of high doses of GC-1 (10×GC-1) did not affect soleus muscle mass.

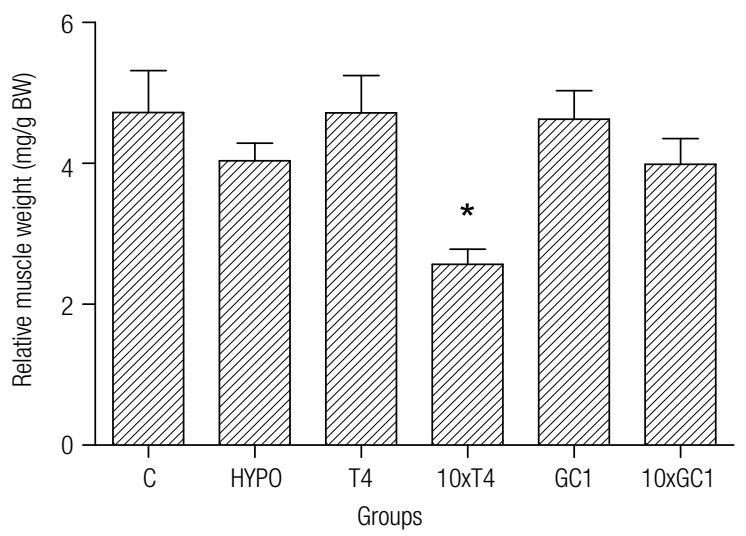

Figure 3. GC-1 did not cause atrophy of the soleus muscle in the rats treated with both physiological (GC-1) and high doses (10×GC-1; $n=8$ rats per group). The diameter of the cardiomyocytes of the left ventricle was measured in the animals in the different groups. * Significant difference in group 10 $\underline{x}$ T4 when compared to the rest. $p \leq 0.05$ in the Newman-Keuls test.

\section{DISCUSSION}

With a growing and aging world population, we have observed over the past decade a significant increase in the prevalence of obesity and diabetes and, consequently, in their comorbidities, which will continue to do so in the future. The prevalence of obesity in the world population increased from $6.4 \%$ in 1980 to $12 \%$ in 2008 (23), and the prevalence of diabetes in the adult population will increase from $6.4 \%$ in 2010 to $7.7 \%$ in 2030 (24). Diverse strategies can be applied to tackle these problems, including pharmacological and nonpharmacological methods such as lifestyle changes, including regular exercise. Among the pharmacological approach, a therapeutic option that has been investigated is the development of selective agonists for the thyroid receptor beta. These ligands have been suggested to help control obesity and hypercholesterolemia without the side effects caused by $\mathrm{TH}$ in the heart, bone and skeletal muscle (13-17). One of these compounds is GC-1, which when administered to animals with hypothyroidism, decreases BW and cholesterol levels without causing tachycardia, arrhythmia, and osteoporosis, or damaging the skeletal tissue of rodents (1316). Nevertheless, none of these studies evaluated the effect of GC-1, or even its analogue, GC-24, on tolerance to exercise in rats with experimentally induced hypothyroidism. Since exercise has been recommended to obesity and metabolic disease treatment, it is very important to investigate whether GC-1 can disrupt exercise capacity.

Here, we investigated the effect of GC-1 on physical tolerance while the animals were in swimming sessions. Our results show that unlike $\mathrm{T}_{4}$, physiological doses and high doses of GC-1 do not modify tolerance to physical exercise in rats with hypothyroidism.

The importance of THs upon tolerance to exercise has been long known, as patients with a hypo or hyperthyroidism display exercise intolerance $(19,20)$.

Physiological studies on exercise show that tolerance to physical effort is a reflex of the combined action of respiratory, cardiovascular, and muscular systems. Therefore, disorders that alter one of these systems, as it is observed in hypo and/or hyperthyroidism, decrease performance during exercise (25).

In our study, we observed a significant decrease in tolerance in hypothyroid rats submitted to physical swimming exercise. This finding confirms previous results, which also observed a lower tolerance to exercise in rats with experimental hypothyroidism (26). The importance of thyroid hormone in physical performance may be associated with the regulation of genetic expression of $\alpha$ and $\beta$ myosin heavy chain in the myocardium by THs (27). Previous studies in rodents found that $\mathrm{TH}$ increases the expression of $\alpha$ myosin heavy chain $(\alpha \mathrm{MHC})$ and, decreases the expression of $\beta$ myosin heavy chain ( $\beta M H C)(28)$. Therefore, hypothyroidism decreases $\alpha \mathrm{MHC}$ expression, reduces cardiac contractility and impairs ejection fraction increment required during physical exercise (19). Thus, the downregulation of $\alpha \mathrm{MHC}$ (fast myosin with higher ATPase activity) and the upregulation of $\beta \mathrm{MHC}$ (slow myosin with low ATPase activity) (29) partially explain the decrease in cardiac contractility associated with hypothyroidism and, consequently, lower tolerance to swimming in the animals with hypothyroidism.

Despite the direct effect on heart function, animals and patients studies have also shown that hypothyroidism is associated with the reduction in blood flow to the skeletal musculature during physical effort $(20,30)$. 
Similarly to our hypothyroid animals, the treatment with high doses of $\mathrm{T}_{4}(10 \times \mathrm{T} 4)$, but not GC-1, also diminished tolerance to swimming effort test (Figure 1). Additionally, animals with hyperthyroidism $(10 \times \mathrm{T} 4$ - Figure 2$)$ exhibited increased cardiomyocyte diameter and ventricular hypertrophy. Prolonged exposure to high concentrations of $\mathrm{TH}$ causes an increase in the myocardium work rate due to blood-volume overload, with inefficient use of energy by the myocardium. Consequently, hypertrophy of the cardiomyocytes is not accompanied by increased efficiency of the cardiac pump since it impairs tolerance to physical exercise (31). The decreased tolerance to exercise with hyperthyroidism may also be related to dysfunction of the skeletal muscle due to the reduced expression of oxidative and glycolytic enzymes (32). Although we did not assess the genetic expression or protein and biochemical content of the skeletal muscle in our study, the animals treated with supraphysiological doses of $\mathrm{T}_{4}$, but not GC-1, presented an atrophy of the soleus muscle.

Previous studies already showed that supraphysiological doses of GC-1 increase energy expenditure without causing tissue damage or altering heart mass (33). GC-1 has no adverse effects on the myocardium and skeletal muscle because TR $\alpha \mathrm{l}$ is predominantly expressed in these tissues (1) and owing to the pharmacokinetic distribution of GC-1 that predominates in other tissues such as liver (34). Collectively, these findings suggest that GC-1 combined with exercise may be safe to treat hypercholesterolemia and or obesity.

In conclusion, our results show that GC-1 administered in physiological and supraphysiological doses does not alter effort tolerance test nor does it modify the diameter of cardiomyocytes. Therefore, GC-l and perhaps other selective $\beta$ thyroid agonists may be used alongside regular physical exercise, the fundamental strategy for the treatment of obesity and other metabolic diseases.

Acknowledgments: we would like to thank Professors Drs. Danielle Rodrigues dos Santos, Elmiro Santos Resende, and Marcelo Emílio Belletti for their help during this study. We would also like to thank Tomas S. Scanlan, Ph.D., T Oregon Health \& Science University, and Paul Webb, Ph.D., The Methodist Hospital Research Institute, for their help with our research on GC-1.

Disclosure: no potential conflict of interest relevant to this article was reported.

\section{REFERENCES}

1. Kahaly GJ, Dillmann WH. Thyroid hormone action in the heart. Endocrine Reviews. 2005;26(5):704-28.

2. Warner A, Mittag J. Thyroid hormone and the central control of homeostasis. J Mol Endocrinol. 2012;49(1):29-35.

3. Williams GR. Thyroid hormone actions in cartilage and bone. Eur Thyroid J. 2013;2(1):3-13.

4. Pramfalk C, Pedrelli M, Parini P. Role of thyroid receptor $\beta$ in lipid metabolism. Biochim Biophys Acta. 2011;1812(8):929-37.

5. Barra GB, Velasco LFR, Pessanha RP, Campos AM, Moura FN, Dias SMG, et al. Mecanismo molecular da ação do hormônio tireoidiano. Arq Bras Endocrinol Metab. 2004;48(1):25-39.

6. Flamant F, Samarut J. Thyroid hormone receptors: lessons from knockout and knock-in mutant mice. Trends Endocrinol Metab. 2003;14(2):85-90.

7. Lazar MA. Thyroid hormone receptors: multiple forms, multiple possibilities. Endocr Rev. 1993;14(2):184-93.

8. Cheng SY, Leonard JL, Davis PJ. Molecular aspects of thyroid hormone actions. Endocr Rev. 2010;31(2):139-70.

9. Rhee SS, Pearce EN. Update: systemic diseases and the cardiovascular system (II). The endocrine system and the heart: a review. Rev Esp Cardiol. 2011;64(3):220-31.

10. Grover GJ, Mellström K, Malm J.Therapeutic potential for thyroid hormone receptor-beta selective agonists for treating obesity, hyperlipidemia and diabetes. Curr Vasc Pharmacol. 2007;5(2):141-54.

11. Baxter JD, Webb P. Thyroid hormone mimetics: potential applications in atherosclerosis, obesity and type 2 diabetes. Nat Rev Drug Discov. 2009;8(4):308-20.

12. Chiellini G, Apriletti JW, Yoshihara HA, Baxter JD, Ribeiro RC, Scanlan TS. A high, affinity subtype-selective agonist ligand for the thyroid hormone receptor. Chem Biol. 1998;5(6):299-306.

13. Grover GJ, Mellström K, Ye L, Malm J, LiYL, Bladh LG, et al. Selective thyroid hormone receptor- $\beta$ activation: a strategy for reduction of weight, cholesterol, and lipoprotein (a) with reduced cardiovascular liability. Proc Natl Acad Sci USA. 2003;100(17):10067-72.

14. Johansson L, Rudling M, Scanlan TS, Lundåsen T, Webb P, Baxter $\mathrm{J}$, et al. Selective thyroid receptor modulation by $\mathrm{GC}-1$ reduces serum lipids and stimulates steps of reverse cholesterol transport in euthyroid mice. Proc Natl Acad Sci U S A. 2005;102(29):10297-302.

15. Freitas FRS, Moriscot AS, Jorgetti V, Soares AG, Passarelli M, Scalan TS, et al. Spared bone mass in rats treated with thyroid hormone receptorTR-selective compound GC-1. Am J Physiol Endocrinol Metab. 2003;285(5): E1135-41.

16. 16. Villicev CM, Freitas FR, Aoki MS, Taffarel C, Scanlan TS, Moriscot AS, et al. Thyroid hormone receptor b-specific agonist GC-1 increases energy expenditure and prevents fat-mass accumulation in rats. J Endocrinol. 2007;193(1):21-9.

17. Miyabara EH, Aoki MS, Soares AG. Thyroid hormone receptor- $\beta$ selective agonist GC-24 spares skeletal muscle type I to II fiber shift. Cell Tissue Res. 2005;321(2):233-41.

18. Grover GJ, Mellstrom K, Malm J. Development of the thyroid hormone receptor $\beta$-subtype agonist KB-141: a strategy for body weight reduction and lipid lowering with minimal cardiac side effects. Cardiovasc Drug Rev. 2005;23(2):133-48.

19. Gonçalves A, Resende ES, Fernandes ML, Costa AM. Effect of thyroid hormones on cardiovascular and muscle systems and on exercise tolerance: a brief review. Arq Bras Cardiol. 2006;87(3):e45-7.

20. Kahaly GJ, Kampmann C, Mohr-Kahaly S. Cardiovascular hemodynamics and exercise tolerance in thyroid disease. Thyroid. 2002;12(6):473-81.

21. Freitas FR, Capelo LP, O'Shea PJ, Jorgetti V, Moriscot AS, Scanlan TS, et al. The thyroid hormone receptor beta-specific agonist GC-1 selectively affects the bone development of hypothyroid rats. J Bone Miner Res. 2005;20(2):294-304. 
22. Lancha Jr AH. Resistência ao esforço físico: efeito da suplementação nutricional de carnitina, aspartato e asparagina [Dissertação]. São Paulo: Universidade de São Paulo, USP; 1991.

23. Stevens GA, Singh GM, LuY, Danaei G, Lin JK, Finucane MM, et al. National, regional, and global trends in adult overweight and obesity prevalences. Popul Health Metr. 2012;10(1):22.

24. Shaw JE, Sicree RA, Zimmet PZ. Global estimates of the prevalence of diabetes for 2010 and 2030. Diabetes Res Clin Pract. 2010;87(1):4-14.

25. Bassett Jr DR, Howley ET. Limiting factors for maximum oxygen uptake and determinants of endurance performance. Med Sci Sports Exerc. 2000;32(1):70-84.

26. Casimiro-Lopes G, Alves SB, Salerno VP, Passos MC, Lisboa PC, Moura EG. Maximum acute exercise tolerance in hyperthyroid and hypothyroid rats subjected to forced swimming. Horm Metab Res. 2008;40(4):276-80.

27. Patel M, MishraV, PawarV, Ranvir R, Sundar R, Dabhi R. Evaluation of acute physiological and molecular alterations in surgically developed hypothyroid Wistar rats. J. Pharmacol Pharmacother. 2013;4(2):110-15.

28. Ojamaa K. Signaling mechanisms in thyroid hormone-induced cardiac hypertrophy. Vascul Pharmacol. 2010;52(3-4):113-9.
29. Wiersinga WM. The role of thyroid hormone nuclear receptors in the heart: evidence from pharmacological approaches. Heart Fail Rev. 2010;15(2):121-4.

30. Xiang GD, Pu J, Sun H, Zhao L, Yue L, Hou J. Regular aerobic exercise training improves endothelium-dependent arterial dilation in patients with subclinical hypothyroidism. Eur $\mathrm{J}$ Endocrinol.2009;161(5): 755-61.

31. Weltman NY, Wang D, Redetzke RA, Gerdes AM. Longstanding hyperthyroidism is associated with normal or enhanced intrinsic cardiomyocyte function despite decline in global cardiac function. Plos One. 2012;7(10):e46655.

32. Kahaly G, Hellermann J, Mohr-Kahaly S, Treese N. Impaired cardiopulmonary exercise capacity in patients with hyperthyroidism. Chest. 1996;109(1):57-61.

33. Venditti P, Chiellini G, Bari A, Di Stefano L, Zucchi R, Columbano A, et al. T3 and the thyroid hormone beta-receptor agonist GC-1 differentially affect metabolic capacity and oxidative damage in rat tissues. J Exp Biol. 2009;212(7):986-93.

34. Trost SU, Swanson E, Gloss B, Wang-Iverson DB, Zhang H, Volodarsky $\mathrm{T}$, et al. The thyroid hormone receptor- $\beta$-selective agonist GC-1 differentially affects plasma lipids and cardiac activity. Endocrinology. 2000;141(9):3057-64. 